\title{
INTEGRASI PENDEKATAN LEVEL DATA PADA LOGISTIC REGRESSION UNTUK PREDIKSI CACAT PERANGKAT LUNAK
}

\author{
Andre Hardoni ${ }^{1}$, Dian Palupi Rini ${ }^{2}$ \\ 1,2Fakultas Ilmu Komputer, Universitas Sriwijaya \\ Email: ${ }^{2}$ andre.hardoni1991@gmail.com, ${ }^{2}$ dprini@unsri.ac.id
}

(Naskah masuk: 29 Maret 2020, diterima untuk diterbitkan: 25 April 2020)

\begin{abstract}
Abstrak
Prediksi awal modul cacat perangkat lunak dapat membantu pengembang perangkat lunak untuk mengalokasikan sumber daya yang tersedia dalam membuat produk perangkat lunak yang memiliki kualitas tinggi yang dapat membatu dalam setiap proses bisnis perusahaan. Perbaikan software setelah pengiriman dan implementasi, membutuhkan biaya jauh lebih mahal dari pada saat pengembangan. Model Logistic Regression (LR) merupakan salah satu model pengklasifikasi yang memiliki kinerja terbaik dalam prediksi cacat softwar, namun kelemahannya adalah rentan terhadap underfitting dataset yang kelasnya tidak seimbang, sehingga menghasilkan penurunan kinerja. Dataset NASA MDP bersifat publik yang banyak digunakan peneliti dalam penelitian prediksi cacat software, namun dataset ini memiliki ketidakseimbangan pada kelas. Untuk menangani masalah ketidakseimbangan kelas pada dataset ini diusulkan metode pendekatan level data yaitu Random Over Sampling (ROS), Random Under Sampling(RUS) dan Synthetic Minority Over-sampling Technique (SMOTE), sehingga pada penelitian ini dilakukan integrasi antara pendekatan level data (ROS, RUS dan SMOTE) dengan model logistic regression dan kemudian membandingkan hasil antara sebelum diintegrasikan dengan sesudah diintegrasikan. Dari hasil percobaan yang dilakukan pada 9 dataset NASA MDP diperoleh hasil bahwa pendekatan level data ROS dan SMOTE yang diintegrasikan pada Logistic Regression dapat meningkatkan kinerja model pengklasifikasi hampir pada seluruh dataset, namun untuk integrasi RUS pada Logistic Regression tidak memperlihatkan adanya perubahan yang signifikan justru ada penurunan nilai AUC pada beberapa dataset pengujian.
\end{abstract}

Kata kunci: cacat perangkat lunak, ketidakseimbangan kelas, pendekatan level data, logistic regression

\section{Integration of Level Data Approaches in Logistic Regression For Software Defect Prediction}

\begin{abstract}
Early predictions of software defect modules can help software developers to allocate available resources in making high-quality software products that can be helped in every company's business processes. Software repair after delivery and implementation, requires more expensive costs than at time of development. Logistic Regression (LR) model is one of the classifier models that have the best performance in software defect prediction [1], but the weakness is that it is vulnerable to underfitting datasets whose classes are not balanced, so can causing in decreased performance. Dataset NASA MDP is public that is widely used by researchers in software defect prediction research, but this dataset has imbalance class. For handling the problem of class imbalance in this dataset, method of data level approach is proposed such as Random Over Sampling (ROS), Random Under Sampling (RUS) and Synthetic Minority Over-sampling Technique (SMOTE), so in this research an integration between the data level approach (ROS, RUS dan SMOTE) and logistic regression model was carried out and then compare intermediate results before integrated with after integrated. From the results of experiments conducted on 9 NASA MDP datasets obtained results that level data approaches ROS and SMOTE integrated in Logistic Regression can improve the performance of the classification model in almost all dataset, however, the integration of RUS in Logistic Regression did not show any significant changes. In fact, there were several AUC values in the dataset which tended to decrease.
\end{abstract}

Keywords: Software defect prediction, class imbalance, level data approach, logistic regression

\section{PENDAHULUAN}


Siklus Hidup Pengembangan Perangkat Lunak (SDLC) terdiri dari lima fase : analisis, desain, implementasi, tes, dan pemeliharaan [2]. Fase-fase ini harus dikerjakan secara efektif untuk memberikan produk perangkat lunak bebas bug dan berkualitas tinggi untuk selanjutnya dapat digunakan oleh pengguna. Mengembangkan produk perangkat lunak bebas cacat adalah tugas yang sangat menantang karena terjadinya bug yang tidak diketahui atau kekurangan yang tidak terdeteksi dapat membuat kualitas produk perangkat lunak menjadi rendah [2]. Prediksi awal modul cacat perangkat lunak dapat membantu pengembang perangkat lunak untuk mengalokasikan sumber daya yang tersedia dalam membuat produk perangkat lunak yang memiliki kualitas tinggi [3] [4]. Prediksi cacat perangkat lunak adalah masalah klasifikasi biner di mana kita harus mengklasifikasikan modul tertentu sebagai cacat atau tidak cacat [5]. Teknik klasifikasi merupakan pendekatan yang poluler untuk memprediksi cacat software [5] dan teknik klasifikasi sendiri dapat difokuskan untuk penentuan kelas cacat dan tidak cacat [3]. Banyak penelitian yang menjadikan teknik klasifikasi menjadi fokus topik penelitiannya. Banyak algoritma klasifikasi yang digunakan dalam penelitian untuk memprediksi cacat software seperti algoritma klasifikasi C4.5, Decision Tree, Linear Regression, Logistic Regression (LR), Nä̈ve Bayes (NB), Neural Network (NN), Random Fores (RF) dan Support Vector Machine (SVM) [1]. Dari hasil komparasi algoritma klasifikasi tersebut diperoleh dua metode algoritma terbaik yaitu Nä̈ve Bayes dan Logistic Regression [1]. Logistic Regression sendiri merupakan klasifikasi linier yang telah terbukti menghasilkan klasifikasi yang powerful dengan statistik probabilitas dan menangani masalah klasifikasi multi kelas [6]. Masalah yang dialami oleh algoritma Logistic Regression adalah masih rentanya terhadap underfitting yaitu keadaan dimana model data training yang dibuat tidak mewakilkan keseluruhan data yang akan digunakan nantinya terlebih pada dataset yang kelasnya tidak seimbang [7], sehingga menghasilkan performa yang buruk dalam pelatihan data.

Dataset NASA (National Aeronautics and Space Administration) yang telah tersedia untuk umum merupakan data metrik perangkat lunak banyak digunakan dalam pengembangan model prediksi cacat software [8]. Dataset NASA masih mengalami ketidakseimbangan (imbalance) kelas [8]. Jumlah data yang cacat (defect) lebih sedikit dari pada jumlah data yang tidak cacat (not defect). Membangun model klasifikasi prediksi cacat software tanpa melakukan pengolahan data awal, tidak akan menghasilkan prediksi yang efektif, karena jika kelas data awal tidak seimbang (imbalance) maka hasil prediksi cenderung menghasilkan kelas mayoritas [8]. Karena data yang cacat merupakan kelas minoritas dari prediksi cacat software, maka banyak cacat yang tidak dapat ditemukan.
Ada tiga pendekatan untuk menangani kelas dataset yang tidak seimbang (unbalance), yaitu pendekatan pada level data, level algoritmik, dan menggabungkan atau memasangkan (ensemble) metode [9]. Pendekatan level data mencakup berbagai teknik resampling, memanipulasi data latih untuk memperbaiki kecondongan distribusi kelas, seperti Random Over-Sampling (ROS), Random UnderSampling (RUS), serta SMOTE (Synthetic Minority Over-sampling Technique) [10]. Resampling juga sebagai sarana mengubah distribusi kelas minoritas sehingga tidak kurang terwakili ketika training data pada algoritma machine learning. Metode resampling sudah terkenal diterapkan untuk memecahkan masalah ketidakseimbangan kelas (class imbalace) [11]. Pada penelitian ini yang akan dilakukan adalah pendektan level data teknik resampling yaitu integrasi ROS, RUS dan SMOTE pada Logistic Regression untuk penyelesaian ketidakseimbangan kelas (class imbalance) pada prediksi cacat software, sehingga dari integrasi tersebut diharapkan didapat perbandingan kinerja pada dataset yang seimbang.

\section{METODE PENELITIAN}

\subsection{Prediksi Cacat Perangkat Lunak (Software)}

Istilah cacat, kesalahan dan bug biasa digunakan secara bergantian. Istilah-istilah ini mengacu pada manifestasi dari kesalahan dalam kode sumber (source code), di mana kesalahan adalah suatu tindakan yang keliru yang dibuat oleh pengembang. Cacat software adalah kekurangan atau cacat pada sebuah software karena melakukan proses yang tak terduga [12]. Tabel 1 di bawah ini menampilkan beberapa contoh umum cacat pada software.

\begin{tabular}{ll}
\multicolumn{2}{c}{ Tabel 1. Contoh umum cacat software } \\
\hline \multicolumn{1}{c}{ Harapan } & \multicolumn{1}{c}{ Cacat } \\
\hline $\begin{array}{l}\text { Software dapat membantu } \\
\text { menyelesaikan pekerjaan }\end{array}$ & $\begin{array}{l}\text { Fungsionalitas sofware } \\
\text { tidak ada }\end{array}$ \\
& $\begin{array}{l}\text { Mengklik tombol, tetapi } \\
\text { tidak ada atau tidak sesuai } \\
\text { dengan proses yang } \\
\text { Mengklik tombol untuk } \\
\text { mengerjakan suatu proses }\end{array}$ \\
& $\begin{array}{l}\text { Tiinginkan } \\
\text { Terjadi kerusakan file } \\
\text { sile dapat di-copy ke lokasi }\end{array}$ \\
lain & pengcopyan \\
\hline
\end{tabular}

Sedangkan Tabel 2 menampilkan contoh nyata cacat software

Tabel 2. Contoh nyata cacat software

\begin{tabular}{ll}
\hline \multicolumn{1}{c}{ Harapan } & \multicolumn{1}{c}{ Cacat } \\
\hline $\begin{array}{l}\text { Software membantu } \\
\text { menghilangkan kesalahan } \\
\text { (contohnya kesalahan } \\
\text { pengejaan) }\end{array}$ & $\begin{array}{l}\text { Tidak dapat mendeteksi } \\
\text { kesalahan ejaan }\end{array}$ \\
$\begin{array}{l}\text { Software dapat merespons } \\
\text { dengan cepat }\end{array}$ & $\begin{array}{l}\text { Respons software } \text { sangat } \\
\text { lambat dari yang } \\
\text { perkiraan }\end{array}$
\end{tabular}


Software aman dari serangan hacker

Hacker dapat

mengekploitasi celah dan melakukan serangan terhadap software

\subsection{Dataset}

Dataset NASA yang telah tersedia untuk umum merupakan data metrik perangkat lunak yang sangat populer dalam pengembangan model prediksi cacat software [13]. Berikut deskripsi dan spesifikasi dataset NASA yang akan ditunjukan pada tabel 3, 4, 5 , dan 6 berikut ini.

Tabel 3. Deskripsi NASA MDP Repository

\begin{tabular}{|c|c|c|c|}
\hline Dataset & Sistem & Bahasa & $\begin{array}{l}\text { Total } \\
\text { Loc }\end{array}$ \\
\hline CM1 & $\begin{array}{l}\text { Instrumen pesawat ruang } \\
\text { angkasa }\end{array}$ & $\mathrm{C}$ & $20 \mathrm{~K}$ \\
\hline JM1 & $\begin{array}{l}\text { Sistem prediksi pendaratan } \\
\text { realtime }\end{array}$ & $\mathrm{C}$ & $315 \mathrm{~K}$ \\
\hline $\mathrm{KC} 1$ & $\begin{array}{l}\text { Manajemen penyimpanan } \\
\text { data lapangan }\end{array}$ & $\mathrm{C}++$ & $18 \mathrm{~K}$ \\
\hline $\mathrm{KC} 3$ & $\begin{array}{l}\text { Manajemen penyimpanan } \\
\text { data lapangan }\end{array}$ & Java & $18 \mathrm{~K}$ \\
\hline $\mathrm{MC} 2$ & Sistem panduan video & $\mathrm{C}, \mathrm{C}++$ & $6 \mathrm{~K}$ \\
\hline PC1 & $\begin{array}{l}\text { Perangkat lunak penerbangan } \\
\text { satelit yang mengorbit bumi }\end{array}$ & $\mathrm{C}$ & $40 \mathrm{~K}$ \\
\hline PC2 & $\begin{array}{l}\text { Simulator dinamis untuk } \\
\text { sistem kontrol perilaku }\end{array}$ & $\mathrm{C}$ & $26 \mathrm{~K}$ \\
\hline PC3 & $\begin{array}{l}\text { Perangkat lunak penerbangan } \\
\text { satelit yang mengorbit bumi }\end{array}$ & $\mathrm{C}$ & $40 \mathrm{~K}$ \\
\hline PC4 & $\begin{array}{l}\text { Perangkat lunak penerbangan } \\
\text { satelit yang mengorbit bumi }\end{array}$ & $\mathrm{C}$ & $36 \mathrm{~K}$ \\
\hline
\end{tabular}

Tabel 4. Spesifikasi Dataset NASA MDP Repository Asli (DS)

\begin{tabular}{ccccc}
\hline Dataset & Atribut & Modul & Cacat & Cacat\% \\
\hline CM1 & 41 & 505 & 48 & $9,50 \%$ \\
KC1 & 22 & 2107 & 325 & $15,42 \%$ \\
KC3 & 41 & 458 & 43 & $9,39 \%$ \\
MC2 & 41 & 161 & 52 & $32,30 \%$ \\
MW1 & 41 & 403 & 31 & $7,69 \%$ \\
PC1 & 41 & 1107 & 76 & $6,87 \%$ \\
PC2 & 41 & 5589 & 23 & $0,41 \%$ \\
PC3 & 41 & 1563 & 160 & $10,24 \%$ \\
PC4 & 41 & 1458 & 178 & $12,21 \%$ \\
\hline
\end{tabular}

Tabel 5. Spesifikasi Dataset NASA MDP Repository Transformasi Pertama (DS')

\begin{tabular}{ccccc}
\hline Dataset & Atribut & Modul & Cacat & Cacat\% \\
\hline CM1 & 38 & 344 & 42 & $12,21 \%$ \\
KC1 & 22 & 2095 & 325 & $15,51 \%$ \\
KC3 & 40 & 200 & 36 & $18,00 \%$ \\
MC2 & 40 & 125 & 44 & $35,20 \%$ \\
MW1 & 38 & 263 & 27 & $10,27 \%$ \\
PC1 & 38 & 735 & 61 & $8,30 \%$ \\
PC2 & 37 & 1493 & 16 & $1,07 \%$ \\
PC3 & 38 & 1099 & 138 & $12,56 \%$ \\
PC4 & 38 & 1379 & 178 & $12,91 \%$ \\
\hline
\end{tabular}

Tabel 6. Spesifikasi Dataset NASA MDP Repository Transformasi Kedua (DS")

\begin{tabular}{ccccc}
\hline Dataset & Atribut & Modul & Cacat & Cacat\% \\
\hline CM1 & 38 & 327 & 42 & $12,84 \%$ \\
JM1 & 22 & 7720 & 1612 & $20,88 \%$ \\
KC1 & 22 & 1162 & 294 & $25,30 \%$ \\
KC3 & 40 & 194 & 36 & $18,56 \%$ \\
MC2 & 40 & 124 & 44 & $35,48 \%$ \\
MW1 & 38 & 250 & 25 & $10,00 \%$ \\
PC1 & 38 & 679 & 55 & $8,10 \%$ \\
PC2 & 37 & 722 & 16 & $2,22 \%$ \\
PC3 & 38 & 1053 & 130 & $12,35 \%$ \\
PC4 & 38 & 1270 & 176 & $13,86 \%$ \\
\hline
\end{tabular}

\subsection{Logistic Regression (Regresi Logistik)}

Melakukan analisis data kategori menggunakan regresi logistik adalah mendapatkan model terbaik dan sederhana untuk menjelaskan hubungan antara keluaran dari variabel respons $(Y)$ dengan variabelvariabel prediktornya $(X)$. Jika variabel $Y$ merupakan variabel biner atau dikotomi dalam artian variabel respons terdiri dari dua kategori yaitu "sukses" $(Y=1)$ atau "gagal" $(Y=0)$, maka variabel $Y$ mengikuti sebaran Bernoulli yang memiliki fungsi densitas peluang:

$f(y i)=\pi(x i) y i(1-\pi(x i)) 1-y i, ; y i=0,1$

sehingga diperoleh:

$y i=0$,

$\operatorname{maka} f(0)=\pi(x i) 0(1-\pi(x i)) 1-0=1-\pi(x i)$,

$y i=1$,

$\operatorname{maka} f(1)=\pi(x i) 1(1-\pi(x i)) 1-1=\pi(x i)$.

Misalkan probabilitas dari variabel respons $Y$ untuk nilai $x$ yang diberikan, dinotasikan sebagai $\pi(x)$. Model umum $\pi(x)$ dinotasikan sebagai berikut :

$$
\pi(x)=\frac{\exp (\beta 0+\beta 1 \mathrm{x} 1+\beta 2 \mathrm{x} 2+\cdots+\beta \mathrm{pxp})}{1+\exp (\beta 0+\beta 1 \mathrm{x} 1+\beta 2 \mathrm{x} 2+\cdots+\beta \mathrm{pxp})}
$$

Persamaan (2) di atas disebut fungsi regresi logistik yang menunjukkan hubungan antara variabel prediktor dan probabilitas yang tidak linear, sehingga untuk mendapatkan hubungan yang linear dilakukan transformasi yang sering disebut dengan transformasi logit. Bentuk logit dari $\pi(x)$ dinyatakan sebagai $g(x)$, yaitu:

$\operatorname{logit}[\pi(x)]=g(x)=\operatorname{in}\left(\frac{\pi(\mathrm{x})}{1-\pi(\mathrm{x})}\right)=$

$\beta 0+\beta 1 x 1+\beta 2 x 2+\cdots+\beta p x p$

Persamaan (3) merupakan bentuk fungsi hubungan model regresi logistik yang disebut model regresi logistik berganda [16].

\section{HASIL DAN PEMBAHASAN}


Dalam percobaan yang dilakukan dengan menggunakan 9 dataset NASA MDP. Model yang diuji yaitu Logistic Regression (LR) dengan mengintegrasikan metode pendekatan level data (ROS, RUS dan SMOTE) untuk menyelasikan masalah ketidakseimbangan kelas.

Hasil percobaan tersebut disajikan pada Tabel 7 yang menunjukan nilai AUC dari setiap model. Nilai AUC digunakan sebagai cara mengevaluasi dan melihat kinerja dari metode pengklasifikasi Logistic Regression.

Nilai AUC tersebut yang kemudian akan dibandingkan antara nilai AUC sebelum diintegrasikan dengan pendekatan level data (ROS, RUS dan SMOTE) dengan sesudah diintegrasikan menggunakan uji T-test sample berpasangan.

\begin{tabular}{|c|c|c|c|c|c|c|c|c|c|}
\hline & \multicolumn{9}{|c|}{ Dataset } \\
\hline & CM1 & $\begin{array}{c}\mathrm{KC} \\
1\end{array}$ & $\begin{array}{c}\mathrm{KC} \\
\mathbf{3}\end{array}$ & $\begin{array}{c}\mathrm{MC} \\
2\end{array}$ & $\begin{array}{c}\text { MW } \\
1\end{array}$ & $\begin{array}{c}\text { PC } \\
1\end{array}$ & $\begin{array}{c}\mathbf{P C} \\
\mathbf{2}\end{array}$ & $\begin{array}{c}\mathbf{P C} \\
\mathbf{3}\end{array}$ & $\begin{array}{c}\mathrm{PC} \\
4\end{array}$ \\
\hline LR & 0,76 & 0,8 & 0,7 & 0,73 & 0,75 & $\begin{array}{c}0,8 \\
4\end{array}$ & $\begin{array}{c}0,8 \\
5\end{array}$ & $\begin{array}{c}0,8 \\
1\end{array}$ & $\begin{array}{c}0,8 \\
9\end{array}$ \\
\hline LR+ROS & 0,88 & 0,81 & 0,78 & 0,78 & 0,85 & $\begin{array}{c}0,9 \\
1\end{array}$ & $\begin{array}{c}0,9 \\
6\end{array}$ & $\begin{array}{c}0,8 \\
3\end{array}$ & $\begin{array}{c}0,8 \\
9\end{array}$ \\
\hline LR+RUS & 0,78 & 0,79 & 0,64 & 0,64 & 0,65 & $\begin{array}{c}0,8 \\
1\end{array}$ & $\begin{array}{c}0,9 \\
5\end{array}$ & 0,8 & $\begin{array}{c}0,8 \\
5\end{array}$ \\
\hline $\begin{array}{c}\text { LR+Smot } \\
\text { e }\end{array}$ & 0,82 & 0,8 & 0,86 & 0,85 & 0,84 & $\begin{array}{c}0,8 \\
7\end{array}$ & $\begin{array}{c}0,9 \\
8\end{array}$ & $\begin{array}{c}0,8 \\
2\end{array}$ & $\begin{array}{c}0,9 \\
1\end{array}$ \\
\hline
\end{tabular}

Pada Tabel 7 di atas dapat dilihat perbandingan nilai AUC sebelum diintegrasikan dengan ROS, RUS dan SMOTE dan sesudah diintegrasikan. Dari tabel tersebut dapat dilihat perubahan kinerja yang terjadi pada LR+ROS dan LR+SMOTE yang hampir setiap nilai AUC pada dataset menunjukan kenaikan nilai kinerja walaupun tidak terlalu signifikan pada beberapa dataset (KC1, PC3 dan PC4), namun untuk LR+RUS hanya menunjukan adanya perubahan kinerja pada CM1 dan PC2 namun pada nilai AUC dataset lain cenderung menurun. Untuk mengetahui peningkatan kinerja setiap model akan ditampilkan pada gambar grafik komparasi model dari masing masing dataset yang diujikan.

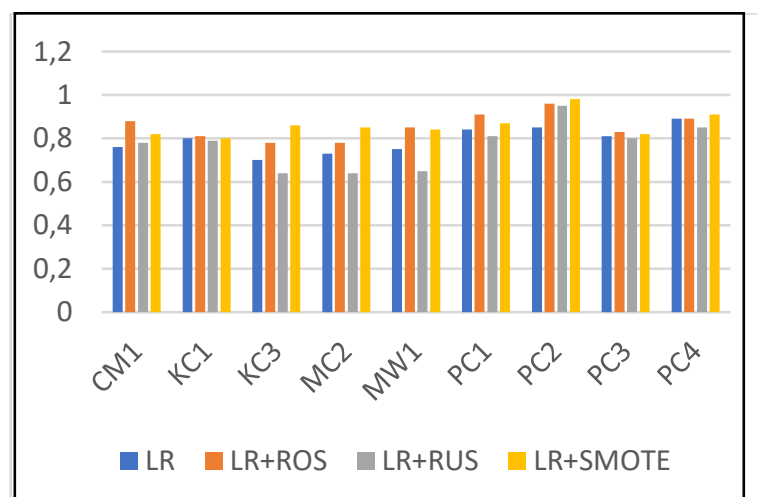

Gambar 2. Grafik Komparasi Model

Pada penelitian ini dilakukan uji komparasi dengan uji sample t-test berpasangan dua sisi (twotailed) antara Logistic Legression (LR) biasa dengan Logistic Regression dengan pendekatan level data (ROS, RUS dan SMOTE).
Untuk uji $t$ (t-test) berpasangan dua sisi (two-tailed) ditetapkan ketentuan sebagai berikut :

Taraf signifikan ditentukan yaitu $\alpha=0,05$.

Jika nilai $P$-value two-tail $<0,05$ Ho ditolak, maka ada perbedaan antara variabel respon dan variabel predictor.

Jika nilai $P$-value two-tail $\geq 0,05$ Ho diterima, maka tidak ada perbedaan antara variabel respon dan variabel predictor.

Untuk uji $t$ ( $t$-test) berpasangan dua sisi (twotailed) untuk variabel nilai AUC LR dan variabel nilai AUC LR+ROS, LR+RUS dan LR+SMOTE dapat dilihat pada Tabel 8, 9 dan 10 .

Tabel 8. Paired sample t-test AUC LR dan LR+ROS

\begin{tabular}{lrr}
\hline & \multicolumn{1}{c}{$L R$} & \multicolumn{1}{c}{$L R+R O S$} \\
\hline Mean & 0,792222 & 0,854444444 \\
Variance & 0,003844 & 0,003727778 \\
Observations & 9 & 9 \\
Pearson Correlation & 0,736698 & \\
Hypothesized Mean Difference & 0 & \\
Df & 8 & \\
t Stat & $-4,1798$ & \\
P(T<=t) one-tail & 0,00154 & \\
t Critical one-tail & 1,859548 & \\
P(T<=t) two-tail & 0,00308 & \\
t Critical two-tail & 2,306004 & \\
\hline
\end{tabular}

Dari hasil uji untuk uji $t$ ( $t$-test) berpasangan dua sisi (two-tailed) pada Tabel 8 dapat ditarik kesimpulan yaitu diketehui nilai $P$-value yang diwakili $P(T<=t)$ two-tail adalah 0,00308. Karena $P$-value lebih kecil dari $\alpha=0,05$ maka Ho ditolak dan $\mathrm{H}_{1}$ diterima sehinggan dapat diartikan ada perbedaan antara hasil performa LR dan LR+ROS.

Tabel 9. Paired sample t-test AUC LR dan LR+RUS

\begin{tabular}{lrr}
\hline & \multicolumn{1}{c}{$L R$} & \multicolumn{1}{c}{$L R+R U S$} \\
\hline Mean & 0,792222 & 0,7677778 \\
Variance & 0,003844 & 0,0112444 \\
Observations & 9 & 9 \\
Pearson Correlation & 0,867785 & \\
Hypothesized Mean Difference & 0 & \\
Df & 8 & \\
t Stat & 1,209229 & \\
P(T<=t) one-tail & 0,130548 & \\
t Critical one-tail & 1,859548 & \\
P(T<=t) two-tail & 0,261096 & \\
t Critical two-tail & 2,306004 & \\
\hline
\end{tabular}

Pada Tabel 9 dapat ditarik kesimpulan yaitu diketehui nilai $P$-value yang diwakili $P(T<=t)$ two-tail adalah 0,261096. Karena nilai $P$-value lebih besar dari $\alpha=$ 0,05 maka Ho diterim dan $\mathrm{H}_{1}$ ditolak, sehingga dapat 
diartikan tidak ada perbedaan antara hasil performa kinerja LR dan LR+RUS.

Tabel 10. Paired sample t-test AUC LR dan LR+SMOTE

\begin{tabular}{lrr}
\hline & \multicolumn{1}{c}{$L R$} & LR+SMOTE \\
\hline Mean & 0,792222 & 0,861111111 \\
Variance & 0,003844 & 0,003036111 \\
Observations & 9 & 9 \\
Pearson Correlation & 0,507755 & \\
Hypothesized Mean Difference & 0 & \\
Df & 8 & \\
t Stat & $-3,53853$ & \\
P(T<=t) one-tail & 0,003818 & \\
t Critical one-tail & 1,859548 & \\
P(T<=t) two-tail & 0,007636 & \\
t Critical two-tail & 2,306004 & \\
\hline
\end{tabular}

Tabel 10 dapat ditarik kesimpulan yaitu diketehui nilai $P$-value yang diwakili $P(T<=t)$ two-tail adalah 0,007636. Karena nilai $P$-value lebih kecil dari $\alpha=$ 0,05 maka Ho ditolak dan $\mathrm{H}_{1}$ diterima, sehingga dapat diartikan ada perbedaan antara hasil performa kinerja LR dan LR+SMOTE.

Berikut hasil kesimpulan uji $t$ sampel berpasangan (paired-sample t-test) yang disajikan pada tabel 11.

Tabel 11. Hasil Rangkuman Uji t-test AUC

\begin{tabular}{ccc}
\hline Model & P-value t-test & Hasil \\
\hline LR+ROS & 0,00308 & Sig $(\boldsymbol{\alpha}<\mathbf{0 , 0 5})$ \\
LR+RUS & 0,261096 & Not Sig $(\alpha>0,05)$ \\
LR+SMOTE & 0,007636 & Sig $(\boldsymbol{\alpha}<\mathbf{0 , 0 5})$ \\
\hline
\end{tabular}

Dari hasil uji $t$ (t-test) berpasangan dua sisi (twotailed) di atas dapat disimpulkan bahwa integrasi pendekatan level data ROS dan SMOTE membuat kinerja metode klasifikasi Logistic Regression (LR) memiliki perbedaan yang signifikan sedangkan untuk RUS tidak lebih baik dari metode LR.

Selain itu untuk mengetahui secara pasti perbedaan antar model maka pada Gambar 3 ditampilkan grafik nilai rata-rata AUC pada setiap model.

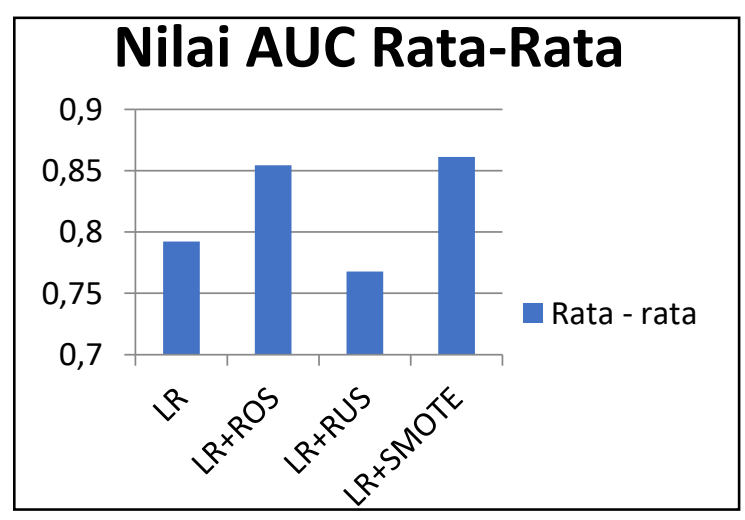

Gambar 3. Grafik nilai AUC rata-rata setiap model

\section{KESIMPULAN}

Dari hasil pengujian dengan menerapkan metode pendekatan level data berupa ROS, RUS, SMOTE untuk penyelesaian ketidakseimbangan kelas (class Imbalance) pada dataset NASA MDP untuk prediksi cacat perangkat lunak dengan algoritma Logistic Regression. Hasil percobaan pada penelitian ini mendapatkan nilai AUC LR+ROS dan LR+SMOTE pada dataset $\mathrm{CM} 1, \mathrm{KC} 3, \mathrm{MC} 2, \mathrm{MW} 1, \mathrm{PC} 1, \mathrm{PC} 2$ mengalami peningkatan yang dapat terlihat signifikan dengan nilai tertinggi pada model LR+SMOTE pada PC2 yaitu 0,98 sedangkan untuk dataset $\mathrm{KC} 1, \mathrm{PC} 3$ dan PC4 naik tidak terlalu signifikan bahkan ada yang sama. Untuk LR+RUS nilai AUC pada CM1 dan PC2 mengalami peningkatan, namun pada nilai AUC dataset lain cenderung menurun dengan nilai terendah 0,64 pada dataset KC3 dan MC2.

Dari hasil pengujian dengan menggunakan uji $t(t$ test) berpasangan dua sisi (two- tailed) dan keseluruhuan rata-rata nilai AUC di atas maka dapat disimpulkan bahwa penerapan model LR+ROS dan LR+SMOTE sanggup menangani ketidakseimbangan kelas dataset dengan menghasilkan nilai AUC lebih tinggi dibandingkan dengan metode LR, namun untuk LR+RUS belum mampu menangani ketidakseimbangan kelas pada dataset karena nilai AUC tidak lebih tinggi dibandingkan dengan metode LR.

\section{DAFTAR PUSTAKA}

[1] T. Hall., S. Beecham., D. Bowes., D. Gray and S. Counsell., 2012."A systematic literature review on fault prediction performance in software engineering," IEEE Transactions on Software Engineering, doi: 10.1109/TSE.2011.103.

[2] D. Tomar and S. Agarwal., 2016. "Prediction of Defective Software Modules Using Class Imbalance Learning," Appl. Comput. Intell. Soft Comput., vol. 2016, pp. 1-12, doi: 10.1155/2016/7658207.

[3] A. Iqbal et al., 2019. "Performance analysis of machine learning techniques on software defect prediction using NASA datasets," Int. J. Adv. Comput. Sci. Appl., vol. 10, no. 5, pp. 300-308, doi: 10.14569/ijacsa.2019.0100538.

[4] D. Bowes., T. Hall and J. Petrić, 2018."Software defect prediction: do different classifiers find the same defects?," Softw. Qual. J., doi: 10.1007/s11219-016-9353-3.

[5] A. Munir., A. Shabib., A. Iftikhar and H. Noureen, 2017."Hybrid Tools and Techniques for Sentiment Analysis: A Review," Int. J. Multidiscip. Sci. Eng., vol. 8, no. 4, pp. 28-33.

[6] S. Canu and A. Smola, 2006."Kernel methods and the exponential family," Neurocomputing, doi: 10.1016/j.neucom.2005.12.009.

[7] C. J. Lin., R. C. Weng and S. Keerthi, 
2008. "Trust region Newton method for largescale logistic regression," J. Mach. Learn. Res., 2008, doi: 10.1145/1390681.1390703.

[8] T. M. Khoshgoftaar., K. Gao., A. Napolitano, and R. Wald., 2014. "A comparative study of iterative and non-iterative feature selection techniques for software defect prediction," Inf. Syst. Front., vol. 16, no. 5, pp. 801-822, 2014, doi: 10.1007/s10796-013-9430-0.

[9] B. W. Yap., K. A. Rani., H. A. Rahman, S. Fong., Z. Khairudin and N. Abdullah, 2014.“An application of oversampling, undersampling, bagging and boosting in handling imbalanced datasets," in Lecture Notes in Electrical Engineering, doi: 10.1007/978-981-4585-187_2.

[10] N. V. Chawla., K. W. Bowyer., L. O. Hall and W. P. Kegelmeyer., 2002."SMOTE: Synthetic minority over-sampling technique," J. Artif. Intell. Res., doi: 10.1613/jair.953.

[11] P. Thanathamathee and C. Lursinsap, "Handling imbalanced data sets with synthetic boundary data generation using bootstrap re-sampling and AdaBoost techniques, 2013." Pattern Recognit. Lett., doi: 10.1016/j.patrec.2013.04.019.

[12] M. McDonald, R. Musson, and R. Smith, 2007.The Practical Guide to Defect Prevention: Microsoft press. US

[13] D. Bowes, D. Gray, T. Hall, S. Counsell, and S. Beecham, 2011."A Systematic Review of Fault Prediction Performance in Software Engineering," IEEE Trans. Softw. Eng.

[14] A. Saifudin, 2014."Pendekatan Level Data dan Algoritma untuk Penanganan Ketidakseimbangan Kelas pada Prediks Cacat Software Berbasis Naïve Bayes,".

[15] D. Zhang, W. Liu, X. Gong and H. Jin, 2011.“A novel improved SMOTE resampling algorithm based on fractal," J. Comput. Inf. Syst. .

[16] D. W. Hosmer and S. Lemeshow., 2000"Applied logistic regression. 2nd Edition.

[17] J. Attenberg and Ş. Ertekin, 2013. "Class imbalance and active learning," in Imbalanced Learning: Foundations, Algorithms, and Applications.

[18] V. López, A. Fernández, and F. Herrera, 2014. "On the importance of the validation technique for classification with imbalanced datasets: Addressing covariate shift when data is skewed," Inf. Sci. (Ny)., doi: 10.1016/j.ins.2013.09.038.

[19] N. Japkowicz, 2013. "Assessment metrics for imbalanced learning," in Imbalanced Learning. Foundations, Algorithms, and Applications.

[20] X. Y. Liu and Z. H. Zhou, 2013. "Ensemble methods for class imbalance learning," Imbalanced Learn. Found. Algorithms, Appl., pp. 61-82, doi: 10.1002/9781118646106.ch4.

[21] D. T. Larose.,2005." Discovering Knowledge in Data: An Introduction to Data Mining.
[22] J. P. Verma, 2013. "Data analysis in management with SPSS software.

[23] M. Shepperd, Q. Song, Z. Sun, and C. Mair, 2013. "Data quality: Some comments on the NASA software defect datasets," IEEE Trans. Softw. Eng., doi: 10.1109/TSE.2013.11.

[24] F. Gorunescu, 2011."Data mining: Concepts, models and techniques," Intell. Syst. Ref. Libr., doi: 10.1007/978-3-642-19721-5. 